\title{
Understanding College Application Decisions Why College Sports Success Matters
}

Devin G. Pope

Jaren C. Pope

Follow this and additional works at: https://repository.upenn.edu/fnce_papers

Part of the Economics Commons, and the Finance and Financial Management Commons

\section{Recommended Citation}

Pope, D. G., \& Pope, J. C. (2014). Understanding College Application Decisions Why College Sports Success Matters. Journal of Sports Economics, 15(2), 107-131. http://dx.doi.org/10.1177/ 1527002512445569

This paper is posted at ScholarlyCommons. https://repository.upenn.edu/fnce_papers/78

For more information, please contact repository@pobox.upenn.edu. 


\title{
Understanding College Application Decisions Why College Sports Success Matters
}

\author{
Abstract \\ Using a unique, national data set that indicates where students choose to send their SAT scores, the \\ authors find that college sports success has a large impact on student application decisions. For \\ example, a school that has a stellar year in basketball or football on average receives up to $10 \%$ more SAT \\ scores. Certain demographic groups (males, Blacks, out-of-state students, and students who played \\ sports in high school) are more likely to be influenced by sports success than their counterparts. The \\ authors explore the reasons why students might be influenced by these sporting events and present \\ evidence that attention/accessibility helps explain these findings. \\ Disciplines \\ Economics | Finance and Financial Management
}




\title{
Understanding College Application Decisions: Why College Sports Success Matters
}

\author{
Devin G. Pope \\ and \\ Jaren C. Pope* \\ RRH: POPE \& POPE: SPORTS AND COLLEGE APPLICATIONS
}


JEL Codes: I230, D010, J240

\begin{abstract}
Using a unique, national dataset that indicates where students choose to send their SAT scores, we find that college sports success has a large impact on student application decisions. For example, a school that has a stellar year in basketball or football on average receives up to 10\% more SAT scores. Certain demographic groups (males, blacks, out-of-state students, and students that played sports in high school) are more likely to be influenced by sports success than their counterparts. We explore the reasons why students might be influenced by these sporting events and present evidence that attention/accessibility helps explain these findings.
\end{abstract}

Devin G. Pope

The Wharton School University of Pennsylvania

3730 Walnut Street, Room 544

Philadelphia, PA 19104

1-215-573-8742

dpope@wharton.upenn.edu

Jaren C. Pope

Agricultural and Applied Economics

Virginia Tech

313 Hutcheson Hall

Blacksburg, VA 24061

1-540-231-4730

jcpope@,vt.edu 


\section{Introduction}

Choosing where to apply to college is both an important and complex decision. Models of college choice typically assume that high school students are fully informed and choose to apply to and eventually attend a school that maximizes their expected, present discounted value of future wages less the costs associated with college attendance (Willis and Rosen 1979; Fuller et al. 1982; Card and Krueger 2004). Thus, variables such as school quality, distance, and tuition should be key predictors of the schools to which students apply and attend. While this choice problem appears daunting, economists typically argue that due to the sizable incentives involved, student outcomes should closely approximate predictions from this rational, decision-making process.

While these classic economic variables are surely important and have been shown to contain predictive power, it is possible that students are not fully informed about all potential options and at times use heuristics when making application decisions. One such case is that students may be more likely to apply to and attend a college that has recently entered a student's consideration set due to an attention-generating event. The degree to which attention/accessibility can affect the college application process and how the size of these effects relate to other classic economic variables such as school quality and tuition costs is an interesting question regarding the college choice process.

In this paper, we attempt to test this hypothesis by focusing on college sports. There is little doubt that the media exposure generated by high-profile college sports such as football and basketball can act as a powerful advertising tool for institutions of higher education. In fact, one might expect that future college applicants are much more likely to be aware of a particular college or university because of the school's appearance in the "final four" of the 
National Collegiate Athletic Association's (NCAA) basketball tournament, rather than the recent hiring of a world-renowned professor. However, college sports success is different from a typical economic variable that predicts college application decisions since it does not necessarily relate to the quality or cost of the academic education that a university provides.

In order to evaluate the impact of sports success on college application decisions, we use an administrative dataset from the College Board that records where students sent their SAT scores - a proxy for where students send their applications. This unique dataset allows us to produce counts for the number and type of students that send their SAT scores to each college that participates in Division I, NCAA basketball or football. Using a fixed effects identification strategy that controls for year and school specific unobserved heterogeneity, we find that there is a large and statistically significant increase in the number of students who send their SAT scores to schools that perform well in recent basketball or football events. For example, we find that a school that makes it to the "final four" in the NCAA basketball tournament or is ranked in the top 10 in the Associated Press Poll at the end of the football season experiences an average increase in sent SAT scores by $6 \%-8 \%$ the following year. Rather than persisting indefinitely, this effect decays to the point of insignificance after 3 years. The results we find are robust to including various school-level controls and trends. Our graphical representation of the results further illustrates how our results are unlikely to be explained by the endogeneity of sports successes or spurious trends that can plague this type of analysis.

Using the demographic information that the SAT data provide, we perform a heterogeneity analysis by identifying the impact of sports on SAT score-sending decisions by demographic sub-groupings. To our knowledge, this is the first attempt to understand which 
types of students are most affected by sports success in the college application process. We find the influence of sports success on males, blacks, out-of-state students, and students who played sports in high school to be significantly higher than their counterparts.

We argue that the large impact of sports success on student application decisions is somewhat puzzling given the classical model of college choice. We posit two key explanations for our findings. First, it is possible that the standard model is adequate and that similar to school quality or costs of attendance, college sports success is simply an important component to a student's utility function ("utility hypothesis"). In fact, given a typical high school student's interests, this hypothesis could very well be driving the results that we find. A second explanation for our findings is that high school students are not fully informed about potential colleges to which they could apply and that their application decisions can be significantly affected by schools that enter their consideration set via attention-generating events like sports ("attention hypothesis"). This hypothesis draws largely on evidence presented in the marketing literature (see for example, Bain (1956) and Nelson (1974) for a discussion of reasons for advertising and Roberts and Lattin (1997) and Manrai and Andrews (1998) for reviews of the consideration set literature).

The empirical relationship between sports success and student applications and how this relationship varies across demographic groups is interesting and important independent of the mechanism driving the results. However, disentangling these two effects is important from a theoretical perspective. If students are simply placing a large weight on sports success in their utility function and subsequently optimizing when making application decisions, then there is little need for changes to current education policy. However, if students are responding to sports success due to the lack of information about college options, this suggests 
that high school students are not being well guided in their college application decisions. Increasing the number of guidance counselors and providing information in other ways may improve student welfare by helping students make better informed college decisions.

Disentangling these two mechanisms is very difficult, and in fact, almost surely the results are caused by some combination of these two stories. We present several pieces of evidence, however, that suggest that the results we find cannot be fully explained by the utility hypothesis. First, a key prediction of attention models is that attention to information from a given event diminishes as the time from the event increases (Fiske and Taylor, 1991). The results we present indicate that the high school student response to sports success decays very quickly across time. Second, we find a larger affect of sports success on out-of-state students than in-state students. While a sports victory for a given school may not change the awareness of in-state students regarding its existence, the sports victory may present a significant shock in attention/awareness for out-of-state students. Third, we estimate the effect of women's basketball success on application decisions. Given the lack of media attention that women's basketball receives relative to men's basketball, one would expect a smaller effect. Indeed, we find no effect of women's basketball success on the number of SAT scores sent to the winning schools. While these results provide evidence suggestive of the attention hypothesis, they can also be explained by the utility hypothesis. For example, while women's basketball generates less attention than men's basketball, it may also be less desirable from the perspective of the utility functions of prospective college students.

Our final test involves a regression discontinuity design using the NCAA basketball tournament. If students are affected by sports success due to the utility hypothesis and care solely for sports victories while they are a student at the school, then they should not be 
affected by sports successes while they are in high school that do not predict future success. We show that schools whose basketball teams "barely" won in a round of the NCAA men's basketball tournament and thus received more attention as they advanced in the tournament, did not have greater success in future years than teams that "barely" lost in the tournament. Yet, the teams that barely won experienced a larger increase in applications than teams that barely lost. While even this test requires certain assumptions, this evidence suggests that attention and not just utility is an important aspect in college application decisions.

The paper proceeds as follows. In section II we provide a brief literature review on college choice and the effect of college sports on application decisions. Section III describes the data that we use in the analysis. In Section IV we outline our empirical strategy. Section V presents our results and Section VI provides a discussion and conclusion.

\section{Literature Review}

College attendance has been an active area of research in economics. College choice in particular has generated substantial discussion. As described in Hossler and Gallagher (1987), college choice decisions have typically been modeled in three general stages: (i) Predisposition: deciding whether to continue formal education beyond secondary education;

(ii) Search: understanding and searching for college attributes that will affect their choice; and

(iii) Choice: constructing a set of schools to apply to and then choosing a school to attend. Most models are essentially reduced-form approximations of the predisposition and choice stages. In fact, a substantial amount of work has been done by researchers in the field of higher education on these two stages (Hossler et al. (1989) provides a dated but useful review of this literature). Most models assume that an individual makes their actual application 
decisions by comparing the benefits and costs of all possible alternatives (Willis and Rosen 1979; Fuller et al. 1982; Card and Krueger 2004). Application decisions (and eventually an enrollment decision) occur by selecting the alternatives that maximize utility subject to a budget constraint. In these models, sports success can impact college choice decisions if students place value on attending a school with a strong sports program.

In this paper, we propose an alternative hypothesis for why college sports might affect student application decisions. Specifically, we argue that it is possible that in the choice phase of the college decision-making process, that students are not fully aware of all possible alternatives. Thus schools that are able to capture the attention of students in some way are more likely to be considered and therefore more likely to receive applications from interested students. The idea that awareness/attention can impact economic decisions has received increased support in the last few years. Given limited attention, it has been argued that individuals will pay attention to expected consequences that are in some way more salient than others (Fiske and Taylor, 1991). Thus, the basic prediction of the theory of limited attention is that agents will pay too much attention to salient stimuli (Barber and Odean, 2004; and Huberman and Regev, 2001) and too little attention to non-salient stimuli (Hong, Torous, and Valkanov, 2002; DellaVigna and Pollet, 2006; and Pope, 2008).

By using college sports success as the attention-generating events that can affect college application decisions, our paper relates to a small literature that has previously estimated the effect of college sports success on college applications. In one of the first papers on the topic, McCormick and Tinsley (1987) hypothesized that schools with athletic success may receive more applications, thereby allowing the school to be more selective in the quality of students they admit. They used data on average SAT scores and in-conference football 
winning percentages for 44 schools for the years 1981-1984, and found some evidence that football success can increase average incoming student quality. Several follow up studies have also been conducted and have produced mixed results (i.e. Bremmer and Kesselring, 1993; Tucker and Amato, 1993; Murphy and Trandel, 1994; and Mixon, 1995). In a recent paper (Pope and Pope, 2008) we addressed some of the data and methodological limitations of previous work and gave clearer evidence that sports success influences college choice. However it left many questions about this process unanswered.

Our paper extends this literature by trying to better explain which students are influenced by sports success and why this influence occurs. This analysis is possible because of an administrative dataset provided by the College Board that records where students sent their SAT scores. These data are highly accurate, have no missing observations, and are available for all schools that participate in Division I basketball or football. The quality of these data is evident from the high degree of significance that we are able to obtain on our point estimates. Using this data we are able to better understand which students are influenced by sports success by estimating the impact separately for different demographic groups. Finally, we add to the current literature by discussing and attempting to disentangle the possible mechanisms for why high school students are responding to sports success.

\section{Data}

\section{$\underline{\text { SAT Data }}$}

The data used in this analysis are obtained from the College Board's Test Takers Database (referred to as SAT database in the remainder of the paper). ${ }^{1}$ The data is at the individual level and represents a $25 \%$ random sample of all SAT test-takers nationwide with 
high school graduation dates between 1994 and 2001. It also includes a 100\% sample of SAT test-takers that are Californians, Texans, African American, or Hispanic. The data are classified by cohorts according to the year in which the students are expected to graduate. For example, the 1994 cohort group contains students that took the SAT who are expected to graduate in the spring of 1994 and apply to begin college the following fall. The SAT database provides demographic and other background information in the Student Descriptive Questionnaire component of the SAT. The data report the SAT score and background characteristics of the most recent test and survey taken. For most students this is at the beginning of their senior year in high school. The dataset identifies the first 20 schools to which a student has requested his/her scores be sent. ${ }^{2}$ The median number of schools to which a student requested his scores be sent was 5 across all years in our sample. We restrict the data to students who sent their scores to at least one of the 332 schools that played NCAA Division I basketball or Division I-A football. We also weight the observations so that the data are representative of all SAT-taking, potential college applicants to each of these 332 schools. $^{3}$

Table 1 presents summary statistics for the data. The Table shows that schools that participate in Division I sports receive on average 7,801 SAT scores each year. Schools that have done well in sports (those in the top ten in football or top eight in basketball at some time between 1994 and 2001) are typically larger schools and receive more SAT scores - 13,779 on average. These numbers will be useful when interpreting the size of the results we find later in the paper.

In this paper, we use sending an SAT score as a proxy for applying to a school. Is this a reasonable proxy? Card and Krueger (2004) (using this same SAT test-takers dataset) tested 
the validity of using sent SAT scores as a proxy for applications. They compared the number of SAT scores that students of different ethnicities sent with admissions records from California and Texas, to administrative data on the number of applications received by ethnicity. They conclude that "trends in the number of applicants to a particular campus are closely mirrored by trends in the number of students who send their SAT scores to that campus, and that use of the probability of sending SAT scores to a particular institution as a measure of the probability of applying to that institution would lead to relatively little attenuation bias."

Since we are using sent SAT scores as a proxy for applications, we obviously do not record students who only take the ACT. Since the ACT is a commonly taken college admissions test, especially in certain parts of the country, it is worth considering whether or not this might bias the effects that we find. If we were to estimate a cross-sectional model, this might be quite problematic. Fortunately, the empirical strategy that we describe in the next section and employ in this paper uses a fixed-effects framework. If the majority of students applying to certain colleges take the ACT as opposed to the SAT, this fact will be treated as unobserved heterogeneity in college applications for a given school in the analysis, and will be netted out. Our estimates will only be biased if the percent of ACT-taking students applying to a given college decreases the year in which the college has a sports victory. We argue that this type of systematic, large change in the population of ACT-taking students being correlated with sports victories is unlikely to explain the results that we find. 


\section{$\underline{\text { Sports Data }}$}

We gathered sports data on NCAA basketball and football success for all 332 schools that participate in NCAA Division I basketball or Division I-A Football. We use the Associated Press's college football poll as our indicator of football success. This poll ranks NCAA division I-A football teams based upon game performances throughout the year. We collected the end of season rankings for teams finishing in the top twenty between the years of 1991 and 2001. ${ }^{4}$ Although this indicator does not incorporate all measures of success (for example, big wins against key rivals, exciting individual player on a team, etc.) it probably proxies these indicators for the top 20 teams each year.

For basketball success, we gather data on team performance in the NCAA men's college basketball tournament. It is widely agreed that this tournament provides the greatest media exposure and indicator of success for a college basketball team (particularly on a national level) each year. "March Madness" as it is often called takes place at the end of the college basketball season in March and the beginning of April. It is a single elimination tournament that determines who wins the college basketball championship. Since 1985, 64

teams have been invited to play each year. ${ }^{5}$ We collected information on all college basketball teams that were invited to the tournament between 1991 and 2001. From this data we create four dummy variables that indicate the furthest round in which a team played: rounds of 64, 16,4 , and champion. We also gathered similar data for women's teams that advanced to the final four and championship games in the women's basketball tournament. 


\section{Empirical Strategy}

\section{Specification}

Many school characteristics cannot be observed by the econometrician, yet these unobservables are likely correlated with both indicators of sports success and the number of applications received by a school. The unobservable component is likely to include information about scholastic tradition, geographic advantages and other information on the quality of the school. Without adequately controlling for these unobservables, they would likely confound the ability to detect the impact of athletic success on student applications.

The nature of the data we have compiled allows us to plausibly control for the unobservables associated with each school. The econometric specification that we employ takes advantage of the panel design of the data. We use a fixed effects model where the fixed effects control for year-specific and school-specific unobserved heterogeneity. We also include a linear trend for each school to try to capture heterogeneous trend rates. We include several additional variables on the right hand side of the equation to further control for quality characteristics of the schools. The econometric specification we use is the following,

(1) $Y^{j}{ }_{i, t}=\alpha_{i, t}+t \lambda_{i}+S_{i, t} \beta+S_{i, t-1} \delta+S_{i, t-2} \gamma+S_{i, t-3} \theta+X_{i, t} \phi+\varepsilon_{i, t}$

where $Y^{j}{ }_{i, t}$ represents the $\log$ number of SAT scores sent to school $\mathrm{i}$ in year $\mathrm{t}$ from the $j^{\text {th }}$ population group. The key covariate $S_{i, t}$ is a vector of dummy variables indicating the level of sports success that school $i$ had during year $t$. We include up to three lags for each sports variable in our model in order to examine persistence in the effects of a winning season on applications. School and Year fixed effects are included along with a linear time trend for 
each school. $X_{i, t}$ is a set of four control variables commonly used in the literature to control for the quality of the school - log total cost to attend school, log average professor salary (lagged one year), log average real income in the state in which the school is located, and the number of public high school diplomas awarded in the state in which the school is located during year $\mathrm{t}^{6}$

\section{Lag Structure}

Understanding when prospective students apply to college in relation to the football and basketball seasons is crucial in determining which lags of our athletic success variables should affect the left-hand side of equation (1). Fall admission application deadlines vary by school. They can occur any time between November and August before the expected fall enrollment period. Furthermore, students often have to send letters of recommendation and SAT scores to the school well before the actual deadlines. Figure 1 illustrates the distribution of application deadlines for our sample of schools in 2003. The label "continuous" in Figure 1 refers to those schools that have a rolling application period rather than a specific deadline. The NCAA Division I-A football season finishes at the beginning of January. The NCAA basketball tournament finishes at the end of March or beginning of April. Therefore, since Figure 1 illustrates that about half of the schools in our sample have application deadlines after April, we might expect some effect on the current year variables. This means that a successful football team that finishes in January or a successful basketball team that finishes in March may still influence application decisions for students enrolling that upcoming fall. However, given the timing of when applications are likely prepared and submitted, one would expect athletic success to have its largest impact when lagged one period (especially for basketball 
which is three months after football). The second and third lags should provide an indication of the persistence of the effect that athletic success has on application rates.

\section{$\underline{\text { Regression Discontinuity Design }}$}

We implement a regression-discontinuity design to analyze the effect of two teams that in a given season show equal sports competence, but receive different levels of attention. It is plausible that teams that just win a NCAA basketball tournament game have similar capabilities to those that just lose. Thistlethwaite and Campbell (1960) first proposed using an observed discontinuity to estimate causal effects. Nonetheless, the presence of an observed discontinuity does not guarantee one can estimate a causal effect. The identifying assumption in our case is that all observable and unobservable pre-event characteristics between the winning and losing teams are not systematically different. For example, it is possible that better teams have the ability to perform at a higher level at the end of games and therefore, even very close games are usually won by the better team. If this is the case, it is not possible to establish a causal relationship using this discontinuity. Ultimately, it is necessary to look at the observable data to generate a convincing argument that the winners and losers are equivalent ex ante.

To make this ex ante comparability argument, we present two pieces of graphical evidence. First, we gather data on the seed of each team in the tournament. ${ }^{7}$ We examine whether or not a discontinuity exists in team seed at the point of just "barely" winning the game. If barely winning is not random, then we might find a significant discontinuity in the average seed for teams that just barely lost compared to teams that just barely won (e.g. better teams are able to "step it up" when a game is close). We also examine whether or not a 
discontinuity exists in the probability that a team makes it to the NCAA tournament the following year based on whether they barely won or lost in the current year. After analyzing these two tests, we run our baseline regression and compare the increase in number of SATsenders for teams that barely won and teams that barely lost and compare the difference in coefficients.

\section{Results}

$\underline{\text { Overall results }}$

The coefficient values and robust standard error bars of the impact of sports success on the log number of SAT scores sent are presented in Table 2 and in Figures 2 and 3. In the Figures (which in our opinion better illustrate the results than Table 2), the open diamonds indicate the coefficient estimates of the effect of current year sports success on the log number of SAT scores sent, while the closed circles, open circles, and open squares indicate the effects of sports success lagged by one, two, and three years, respectively. The top panel in Figure 2 indicates the coefficient values for making it into the NCAA basketball tournament (round of 64). The other panels in Figure 2 and Figure 3 present the coefficient values for achieving the different levels of sports success that we have discussed. Column 1 presents the effect of sports success on the log number of total SAT senders. Subsequent columns present the effect of sports success on the log number of SAT senders in different subgroups.

Looking down column 1 of Figures 2 and 3 we find that being one of the 64 teams in the NCAA tournament yields approximately a $2 \%$ increase in the total number of SAT score senders the following year (the closed circle), making it to the "sweet sixteen" yields a 5\% increase, making it to the "final four" a $6 \%$ increase, and being the champion a $11 \%$ increase. 
For football, the results suggest that ending the season ranked in the top 20 results in a $2 \%$ increase in score senders the following year, ending in the top 10 yields a $6 \%$ increase, and ending as the football champion yields a $12 \%$ increase in score senders the following year. As was expected, there appears to be some effect on the current football sports variables (the football season ends three months before the basketball season) but little effect on the current basketball sports variables. The effects are large and significant on the first and second lags, while by the third lag the effects are usually diminished to a small magnitude and are insignificant. Almost all coefficients on the first and second lag variables are significant at the one percent level. These results suggest that the better the sports team performs the more applications a college will receive.

Looking across the columns in Figures 2 and 3, we find very distinct responses to athletic success from different groups of students. Blacks are roughly twice as responsive to basketball success as any other race. For example, making it into the final four yields a $14 \%$ increase in black SAT scores sent $($ s.e. $=2.6)$ compared to a $7 \%$ increase $($ s.e. $=1.2)$ for the overall population. The basketball champion in a given year receives on average $20 \%$ more black SAT scores sent for each of the next two years. Hispanics and blacks are the two races most likely to be affected by football success. Asians are the least likely to be affected by either sport. The results indicate that males respond more to sports success than females. Similarly, the coefficients on the students who played basketball or football in high school are generally at least twice as large as those of students who did not play sports. Both out-of-state and in-state students are affected by sports success, but out-of-state students are on average affected more. 
Using the data on the final four and championship rounds of the women's college basketball tournament, we perform regressions again following the specification in equation (1). In Table 3, we present the results from these specifications using women's basketball sports variables. Column (1) uses the log number of SAT scores sent as the dependent variable. Column (2) uses the log number of SAT scores sent by females as the dependent variable. The results indicate that women's basketball does not have any impact on the total number of SAT scores sent or on the number of SAT score sent from women that a school receives.

\section{$\underline{\text { Regression Discontinuity Results }}$}

Finally, we present the results from the regression discontinuity analysis. Figures 4 and 5 are produced by aggregating all rounds of the NCAA tournament and plotting the seed (Figure 4) and the probability that the team makes it to the following year's NCAA tournament (Figure 5) by the point difference in the current year's tournament game. As can be seen in these Figures, teams that have a larger margin of victory have a lower seed (better placement) in the tournament and are more likely to go to the following year's tournament. However, it is important to note that there does not appear to be a discontinuity at 0 points. In other words, if the analyzed margin is small enough (win by less than 1 or 2 points), then the teams that win have similar seeds and are equally likely to make the tournament the following year.

Table 4 shows how students respond to teams that barely win relative to teams that barely lose by running our baseline specification on teams that win and for teams that lose by 1 or 2 points. As can be seen in the Table, teams that barely win and teams that barely lose 
both see a spike in applications the following year. This is reasonable given that both the winning and losing teams at least made it to the tournament that year. However, the teams that barely won on average experienced a spike in applications that is approximately twice the size of the spike received by teams that barely lost. This suggests that students were more likely to be influenced by teams that barely won and thus moved on in the tournament than teams that barely lost. If students are solely interested in how well a sports program will perform once they arrive at a school and they have correct beliefs regarding how moving on in the tournament (even by a small margin) is related to future sports success, then teams that barely won should receive the same bump in applications as teams that barely lose according to the classical model. If these assumptions hold, then this evidence suggests that the awareness/attention generated by moving on in the tournament had an impact on student application decisions.

\section{Discussion and Conclusion}

Overall, our results provide clear evidence regarding a link between college sports success and student applications. Using a dataset that allows us to identify where a student sends his/her applications and an identification strategy that controls for school-specific unobservables, we find that a school which has a good sports year receives an increase in sent SAT scores the following year. These increases can be quite dramatic. A school that is invited to the NCAA basketball tournament can on average expect an increase in sent SAT scores in the range of $2 \%$ to $11 \%$ the following year depending on how far the team advances in the tournament. The top 20 football teams also can expect increases of between $2 \%$ and $12 \%$ the following year. We are also able to explore which students are influenced by sports 
success. Our heterogeneity analysis shows that there is substantial heterogeneity in these results across different demographic groups with blacks, males, out-of-state students and students who played basketball and football in high school being more responsive than their demographic counterparts.

How does the size of the effects that we find relate to more classic economic variables? In the college choice literature, the application elasticity with respect to changes in the price of attending college has been found to range from -0.25 to -1.0 (see, for example, Curs and Singell (2002) and Savoca (1990)). Assuming that sending SAT scores is similar to sending an application, these elasticities suggest that tuition/financial aid would have to be adjusted by $6-32 \%$ to obtain a similar increase in applications as is found by making it to the Final Four in basketball or being in the top ten in football. A comparison can also be made to the effect of changes in "school quality" as measured by changes in US News and World Report rankings. Using the estimates and assumptions made in Pope (2007) which looks at the effect of US News Rankings on college choices, making it into the Final Four in basketball or the top ten in football is approximately equivalent to the effect that is found on applications when a school's rank is improved by half (e.g. $20^{\text {th }}$ to $10^{\text {th }}$ or $8^{\text {th }}$ to $4^{\text {th }}$ ).

Given these large effects, the results presented in this paper should be of obvious importance and interest to college administrators interested in understanding how best to improve the desirability of their school in the eyes of high school students. However, these results also relate to an increasingly important academic debate on modeling how consumers make difficult decisions. Specifically, we attempt to disentangle two mechanisms that could be driving the results that we find. We present several pieces of evidence that jointly suggest that sports success may cause students to simply become aware of a school's existence which 
can increase the number of sent SAT scores. Perhaps the strongest evidence is that students respond to sports teams that receive a lot of attention (move on in the NCAA tournament albeit by a small margin of victory) yet are no more likely to have success after a student's matriculation.

While not fully conclusive, the results we present suggest that students can be affected by events that do not change the quality or costs of a school but that capture a student's attention. Thus a major contribution of this paper is to show how attention generating events appear to affect choices in a setting with an unusually high level of economic importance. Furthermore, it suggests that high school students are not being well guided in their college application decisions. Perhaps increasing the number of guidance counselors and providing information in other ways may improve student welfare by helping students make better informed decisions on where to attend college. A final concluding point to make is that our analysis was done in a "revealed preference" setting where we simply observed the choices made by college applicants and related these choices to the timing of college sports successes. Future research may consider enriching the analysis by analyzing "stated preference" information from college students on what factors influenced their college decisions concurrently with revealed preference information. 


\section{References}

Bain, J. S. Barriers to New Competition. Cambridge, MA: Harvard University Press, 1956.

Barber, B. M. and T. Odean. "All that Glitters: The Effect of Attention and News on the Buying Behavior of Individual and Institutional Investors.” mimeo, 2002.

Bremmer, D., and R. Kesselring. "The Advertising Effect of University Athletic Success-A Reappraisal of the Evidence." Quarterly Review of Economics and Finance, 33(4), 1993, 409421.

Card, D., and A. Krueger. "Would the Elimination of Affirmative Action Affect Highly Qualified Minority Applicants? Evidence from California and Texas." NBER Working Paper \# 10366, 2004.

Curs, B. and L. D. Singell. "An Analysis of the Application and Enrollment Process for InState and Out-of-State Students at a Large Public University." Economics of Education Review, 21, 2002, 111-124.

DellaVigna, S. and J. Pollet. "Attention, Demographics, and the Stock Market.” mimeo, 2006.

Fiske, S. T. and S. E. Taylor. Social Cognition. New York: McGraw-Hill, Inc., 1991.

Fuller, W., C. Manski, and D. Wise. "New Evidence on the Economic Determinants of Postsecondary Schooling Choices." Journal of Human Resources, 17, 1982, 477-498.

Hong, H., W. Torous, and R. Valkanov. "Do Industries Lead the Stock Market?" mimeo, 2003.

Hossler, D., and L. Gallagher. "Studying college choice: A three-phase model and the implication for policy makers." College and University, 2, 1987, 207-221.

Hossler, D., J. Braxton, and G. Coopersmith. "Understanding Student College Choice." in John C. Smart (Ed.) Higher Education: Handbook of Theory and Research, 5, 1989, 231-288.

Huberman, G., and T. Regev. "Contagious Speculation and a Cure for Cancer: A Nonevent that Made Stock Prices Soar.” Journal of Finance, Vol. 56, 2001, 387-396.

Manrai, A. K. and R. L. Andrews. "Two-stage Discrete Choice Models for Scanner Panel Data: An Assessment of Process and Assumptions." European Journal of Operational Research, 111, 1998, 193-215.

McCormick, R., and M. Tinsley. "Athletics versus Academics? Evidence from SAT Scores." Journal of Political Economy, 95, 1987, 1103-1116. 
Mixon, F. "Athletics versus Academics? Rejoining the Evidence from SAT Scores." Education Economics, 3, 1995, 277-283.

Murphy, R., and G. Trandel. "The Relation between a University's Football Record and the Size of Its Applicant Pool." Economics of Education Review, 13, 1994, 265-270.

Nelson, P.H. “Advertising as Information.” Journal of Political Economy, 81, 1974, 729-745.

Pope, D. "Reacting to Rankings: Evidence from 'America's Best Hospitals and Colleges'." Mimeo, 2007.

Pope, J. C. "Buyer Information and the Hedonic: The Impact of a Seller Disclosure on the Implicit Price for Airport Noise." Journal of Urban Economics, 63, 2008, 498-516.

Pope, D. and J. C. Pope. "The Impact of Sports Success on the Quantity and Quality of Student Applications." forthcoming Southern Economic Journal, 2008.

Roberts, J., and J. Lattin. "Consideration: Review of Research and Prospects for Future Insights." Journal of Marketing Research, 34, 1997, 406-410.

Savoca, E. "Another Look at the Demand for Higher Education: Measuring the Price Sensitivity of the Decision to Apply to College." Economics of Education Review, 9, 1990, 123-134.

Thistlethwaite, D., and D. Campbell. "Regression discontinuity analysis: an alternative to the ex post facto experiment." Journal of Educational Psychology, 51, 1960, 309-317.

Tucker, I., and L. Amato. "Does Big-Time Success in Football or Basketball Affect SAT Scores?" Economics of Education Review, 12, 1993, 177-181.

Willis, R., and S. Rosen. "Education and Self-Selection." Journal of Political Economy, 87, 1979, 7-36. 
*We wish to thank David Bell, Jonah Berger, David Card, Stefano DellaVigna, Arden Pope, Matthew Rabin and V. Kerry Smith for useful comments that greatly strengthened the manuscript. The authors are also grateful for feedback from Jared Carbone, Charles Clotfelter, Nick Kuminoff, John Siegfried, Wally Thurman, Sarah Turner, and participants of the NBER's Higher Education Working Group.

Authors: Devin G. Pope, assistant professor of operations and information management, The Wharton School, University of Pennsylvania, Philadelphia, PA. Phone 1-215-573-8742, Email dpope@wharton.upenn.edu. Jaren C. Pope, assistant professor of agricultural and applied economics, Virginia Tech, Blacksburg, VA. Phone 1-540-231-4730, E-mail jcpope@,vt.edu. 


\footnotetext{
${ }^{1}$ We thank David Card, Alan Krueger, the Andrew Mellon Foundation, \& the College Board for help in gaining access to this dataset.

${ }^{2}$ Less than $1 \%$ of students sent their scores to more than 14 schools.

${ }^{3}$ The weight is 1 for observations from students who are included in the sample with probability 1 and 4 for those who are included in the sample with probability .25 .

${ }_{5}^{4}$ Sports data can be obtained at www.infoplease.com.

${ }^{5}$ Currently, 65 teams are actually invited, but 2 teams are required to win an additional game before entering the round of 64 .

${ }^{6}$ The data for these control variables were gathered from the Integrated Post Secondary Education Survey conducted by the national Center of Education and from the Bureau of Labor Statistics' website.

${ }^{7}$ The seed of each team represents the rank that they received coming into the tournament. In the current NCAA tournament, teams are seeded between 1 and 16 ( 1 being the best). 4 teams are given each seed number.
} 


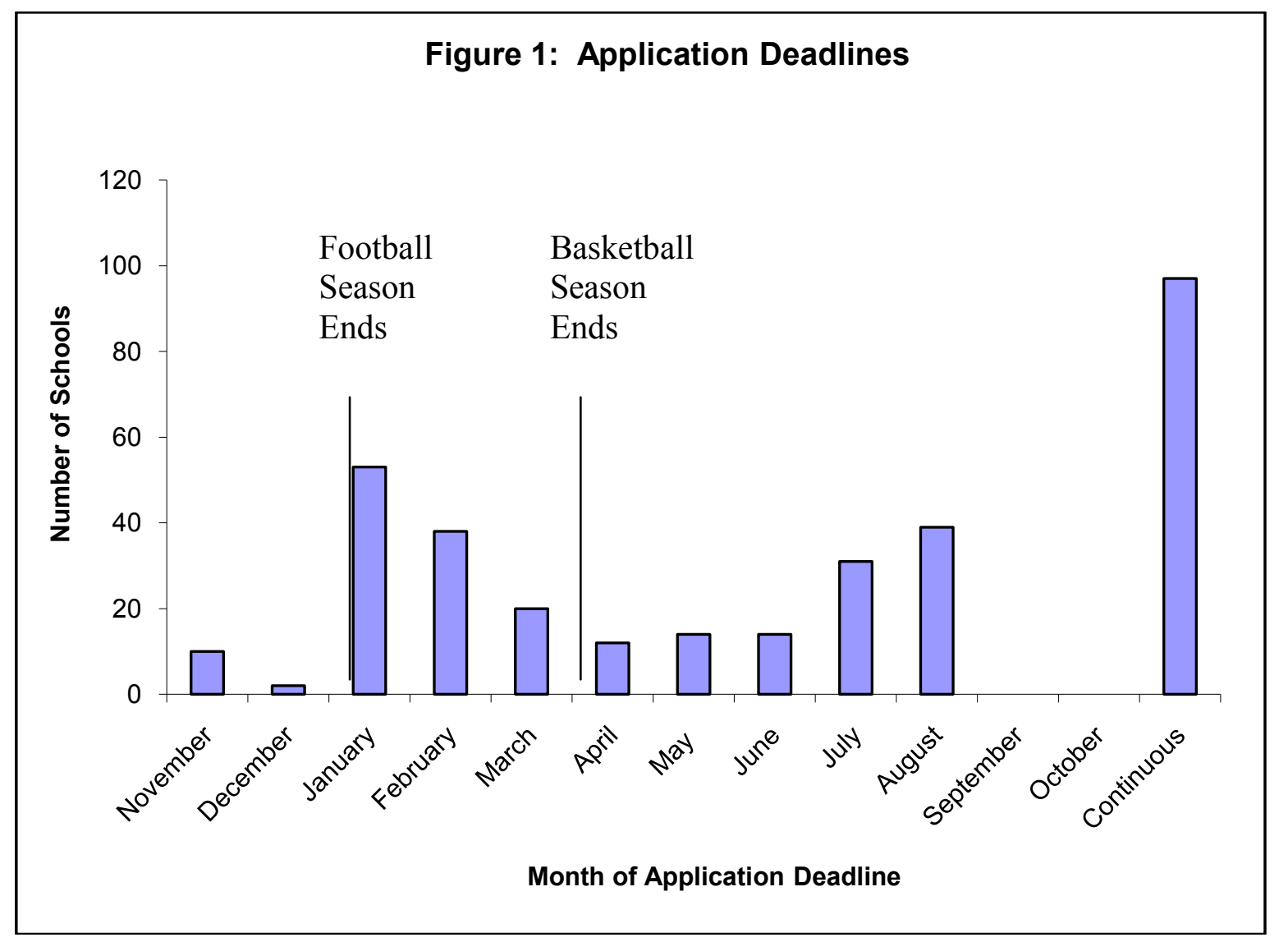

Notes: The figure includes all schools that compete in Division I football or basketball. Application deadline data is based on 2003 information from a licensed dataset from Peterson's (a part of the Thompson Corporation). 


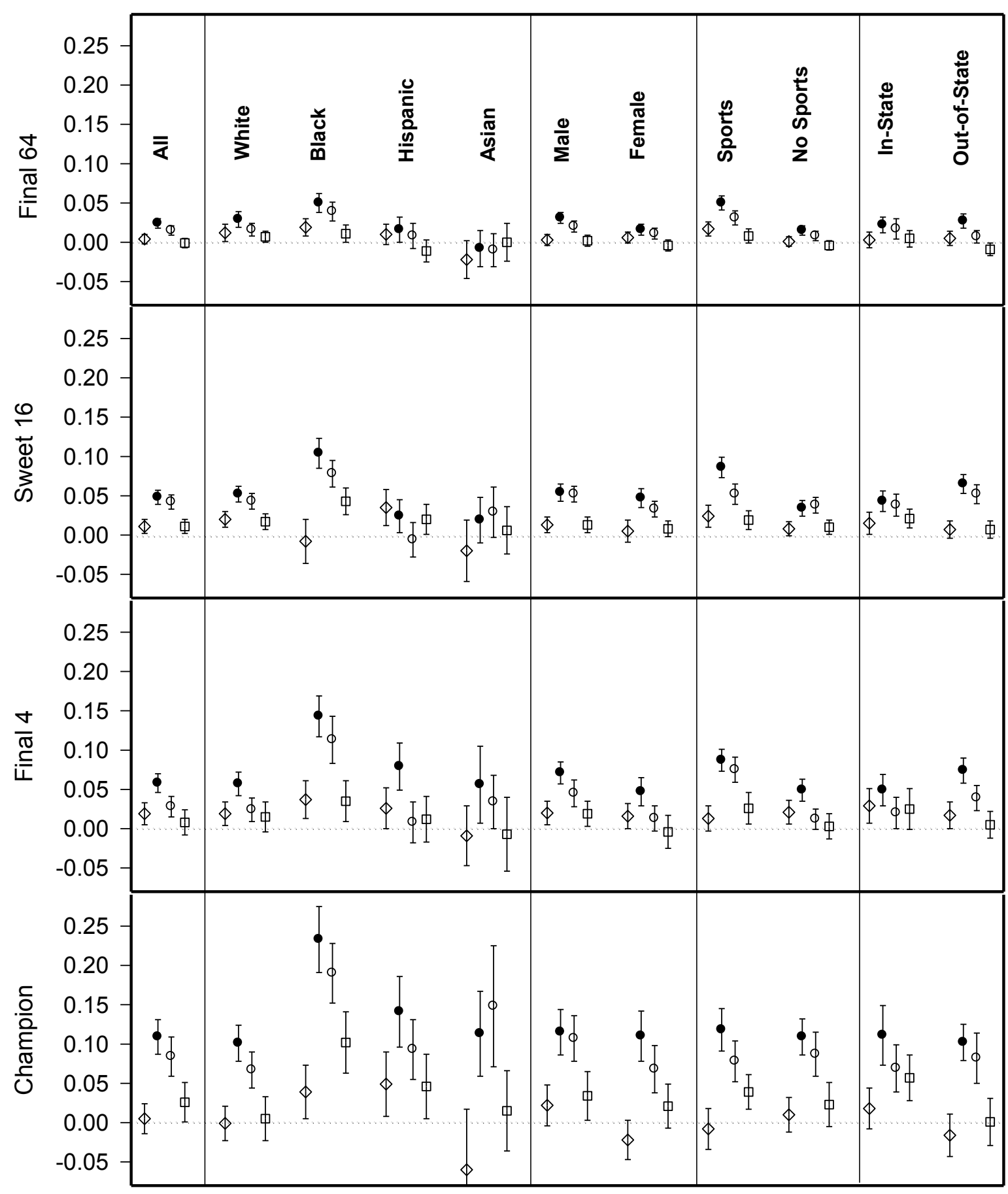

Figure 2. Regression coefficients (and SE bars) for basketball success compared across levels of success; across race, sex, high school sports participation, and in-versus out-of-state categories; and for different lags (open diamond denotes concurrent year; closed circle, one-year lag; open circle, two-year lag; open square, three-year lag). 


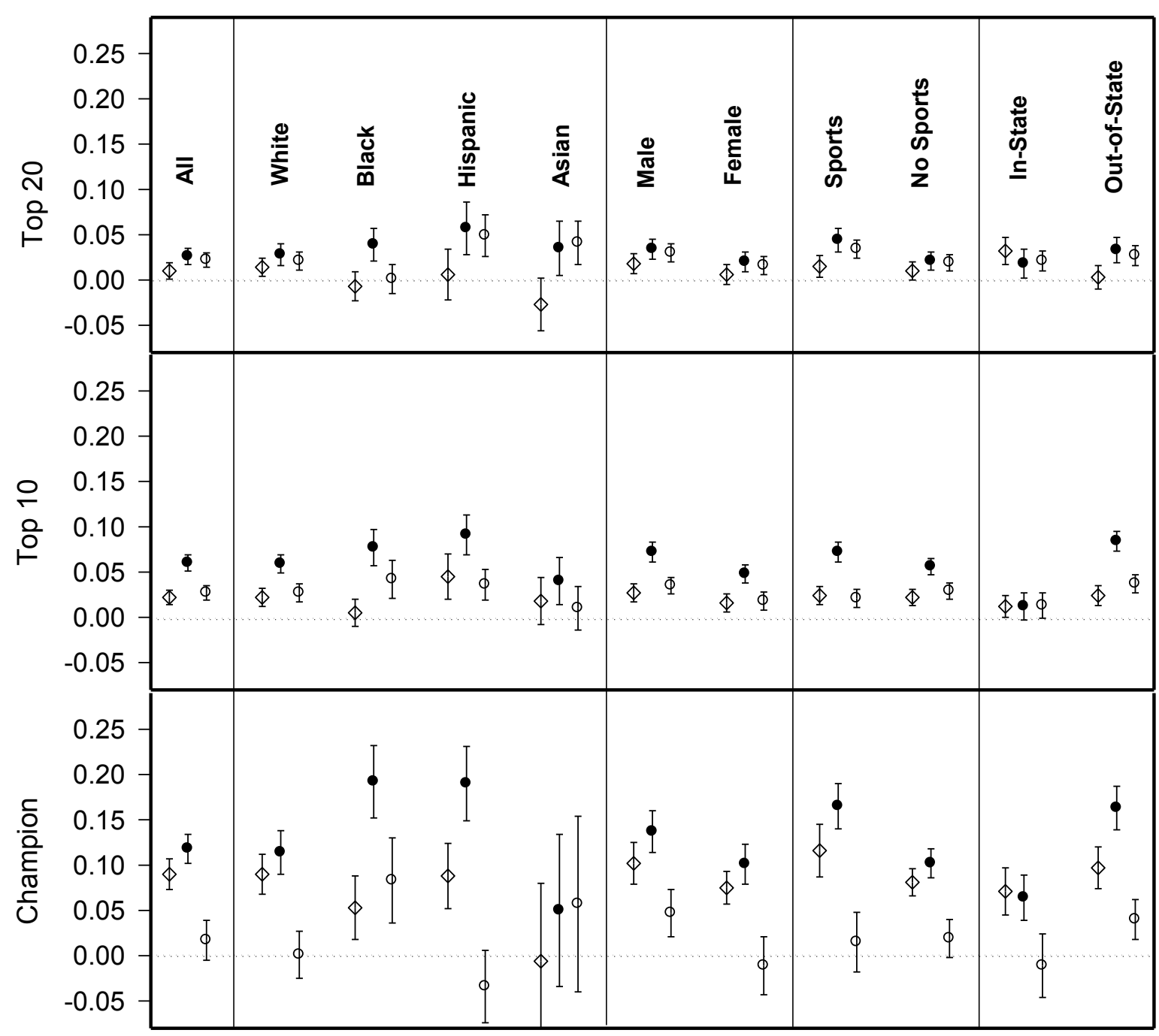

Figure 3. Regression coefficients (and SE bars) for football success compared across levels of success; across race, sex, high school sports participation, and in-versus out-of-state categories; and for different lags (open diamond denotes concurrent year; closed circle, one-year lag; open circle, two-year lag). 
Figure 4. Average Seed by Point Difference

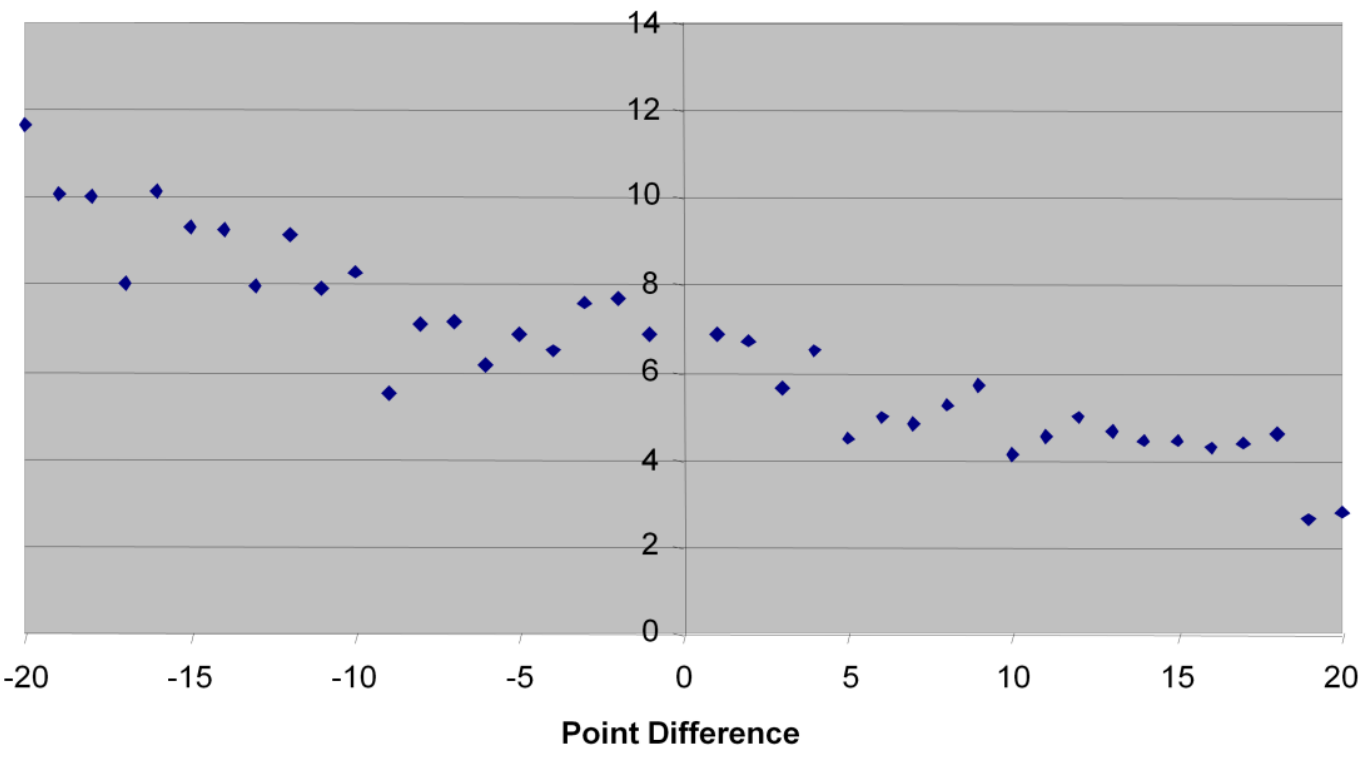

Notes: The Figure aggregates all NCAA basketball tournament data from 1992-2001. Every game played (in any round of the tournament) is included in the figure. The seed of the team is on the vertical axis (seeds range from 1-16) and the final point difference is on the horizontal axis. 


\section{Figure 5. Percent Making it to Tournament in Year $t+1$ by Point Difference in Year $t$}

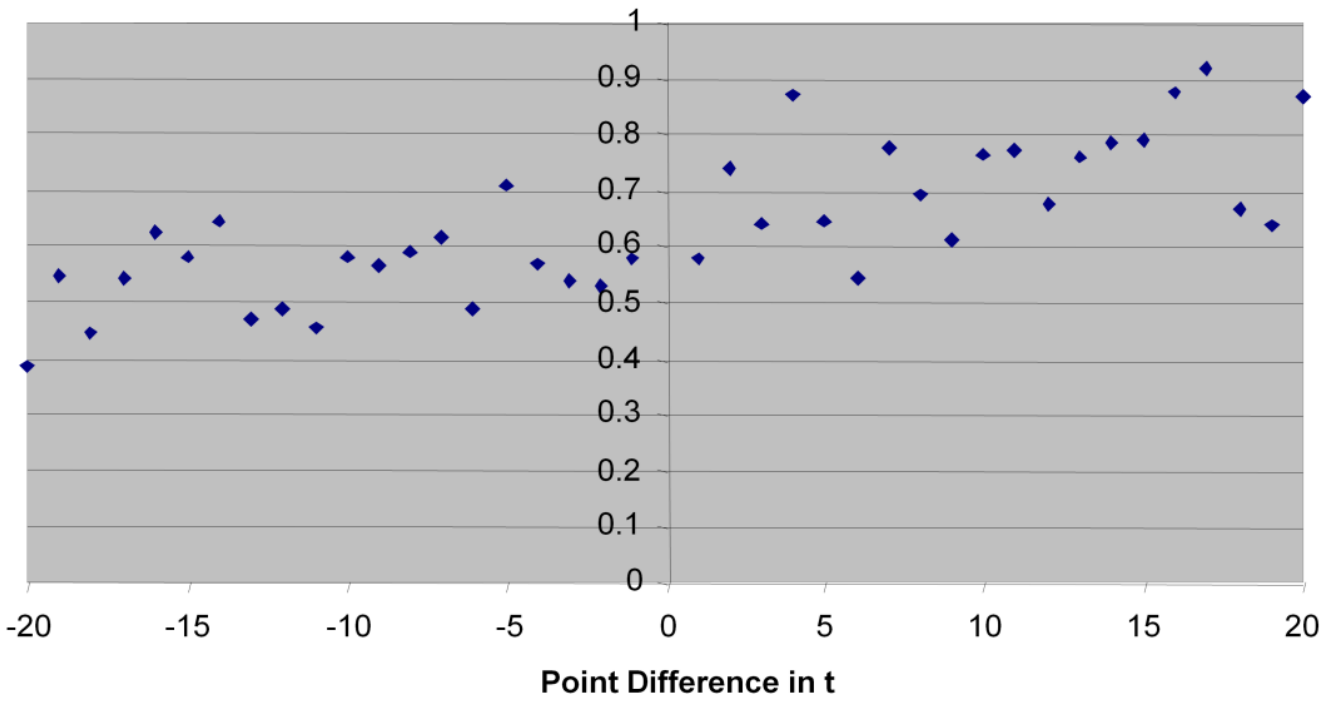

Notes: The Figure aggregates all NCAA basketball tournament data from 1992-2001. Every game played (in any round of the tournament) is included in the figure. The vertical axis indicates the fraction of teams that made it to the NCAA basketball tournament in the following year while the horizontal axis indicates the final point difference in the current year's games. 
Table 1. Summary Statistics

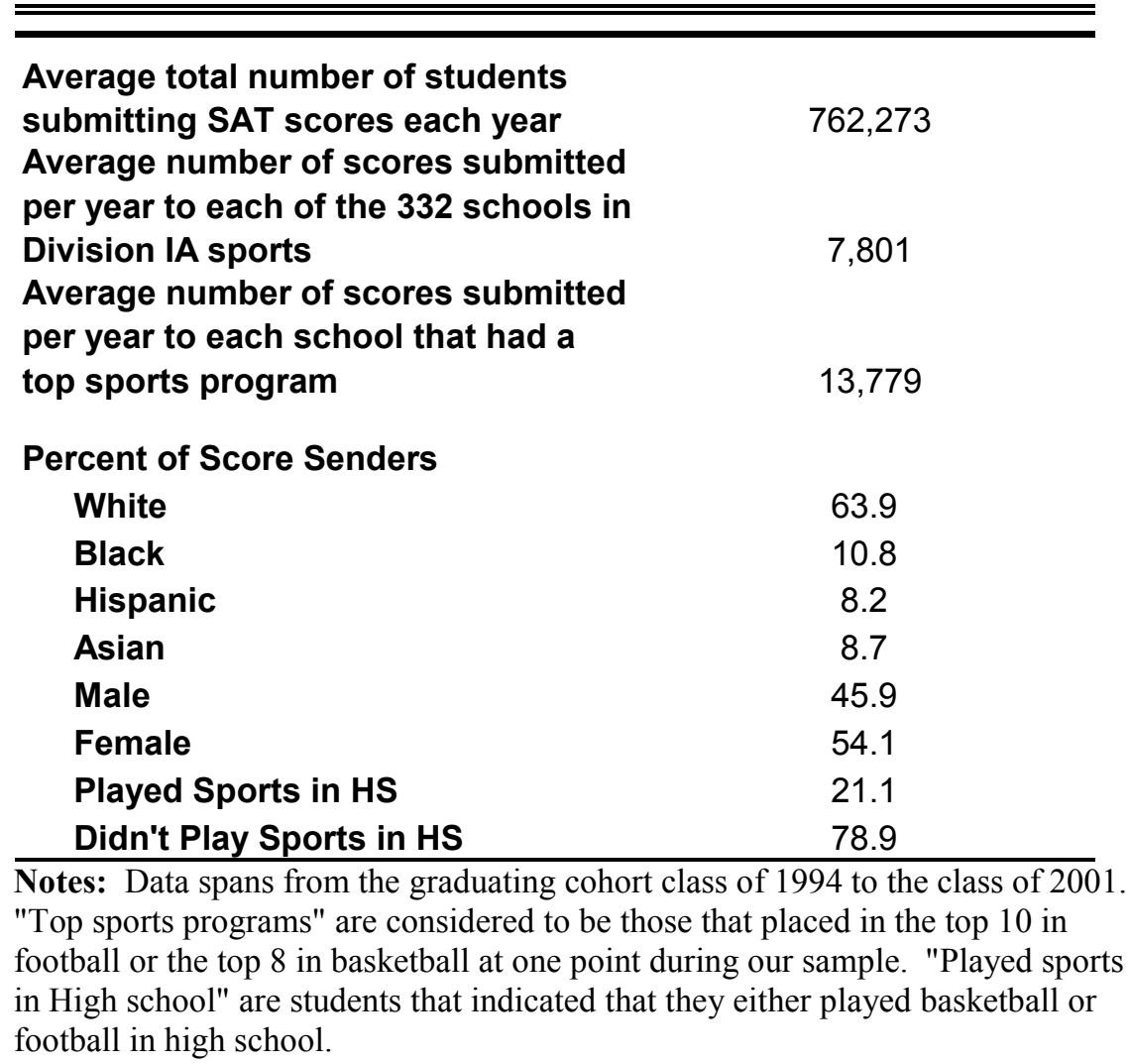


Table 2A. The Impact of Success in Men's Basketball and Football on SAT Score Sending

\begin{tabular}{|c|c|c|c|c|c|c|c|c|c|c|c|}
\hline \multicolumn{12}{|c|}{ Dependent Variable: Log Number of SAT Scores Sent by Subgroup } \\
\hline & Everyone & White & Black & Hispanic & Asian & Males & Females & Sports & No Sports & In-State & Out-of-State \\
\hline \multicolumn{12}{|l|}{ Basketball } \\
\hline \multirow[t]{2}{*}{ Final_64 } & 0.004 & 0.012 & 0.019 & 0.01 & -0.022 & 0.003 & 0.006 & 0.017 & 0.001 & 0.003 & 0.005 \\
\hline & [0.006] & [0.011] & [0.011] & [0.013] & [0.024] & [0.007] & {$[0.007]$} & [0.009] & {$[0.006]$} & [0.010] & [0.009] \\
\hline \multirow[t]{2}{*}{ Final_64_lg1 } & 0.024 & 0.029 & 0.05 & 0.016 & -0.008 & 0.031 & 0.016 & 0.05 & 0.015 & 0.022 & 0.027 \\
\hline & {$[0.006]^{\star *}$} & {$[0.010]^{\star *}$} & {$[0.012]^{* *}$} & [0.016] & [0.023] & {$[0.007]^{\star *}$} & {$[0.007]^{*}$} & {$[0.009]^{* *}$} & {$[0.006]^{*}$} & {$[0.010]^{*}$} & {$[0.009]^{* *}$} \\
\hline \multirow[t]{2}{*}{ Final_64_Ig2 } & 0.015 & 0.016 & 0.039 & 0.008 & -0.01 & 0.02 & 0.011 & 0.031 & 0.008 & 0.017 & 0.007 \\
\hline & {$[0.006]^{*}$} & {$[0.008]^{*}$} & {$[0.012]^{* *}$} & [0.016] & [0.021] & {$[0.007]^{\star *}$} & [0.007] & {$[0.009]^{* *}$} & [0.006] & [0.013] & [0.008] \\
\hline \multirow[t]{2}{*}{ Final_64_Ig3 } & -0.001 & 0.007 & 0.011 & -0.011 & 0 & 0.002 & -0.004 & 0.008 & -0.004 & 0.005 & -0.009 \\
\hline & {$[0.006]$} & {$[0.007]$} & [0.011] & {$[0.014]$} & {$[0.024]$} & {$[0.007]$} & [0.007] & [0.009] & {$[0.006]$} & {$[0.011]$} & {$[0.008]$} \\
\hline \multirow[t]{2}{*}{ Final_16 } & 0.011 & 0.02 & -0.008 & 0.035 & -0.02 & 0.013 & 0.005 & 0.024 & 0.008 & 0.015 & 0.007 \\
\hline & [0.009] & {$[0.010]^{*}$} & [0.028] & [0.023] & [0.039] & {$[0.010]$} & [0.014] & [0.014] & [0.009] & [0.014] & [0.011] \\
\hline \multirow[t]{2}{*}{ Final_16_lg1 } & 0.048 & 0.052 & 0.104 & 0.024 & 0.019 & 0.054 & 0.047 & 0.086 & 0.034 & 0.043 & 0.065 \\
\hline & {$[0.009]^{\star *}$} & {$[0.010]^{\star *}$} & {$[0.019]^{* *}$} & [0.021] & [0.029] & {$[0.011]^{\star *}$} & {$[0.012]^{\star *}$} & {$[0.013]^{* *}$} & {$[0.010]^{* *}$} & {$[0.013]^{\star *}$} & {$[0.012]^{\star *}$} \\
\hline \multirow[t]{2}{*}{ Final_16_lg2 } & 0.042 & 0.043 & 0.078 & -0.006 & 0.029 & 0.052 & 0.033 & 0.052 & 0.038 & 0.038 & 0.052 \\
\hline & {$[0.009]^{\star *}$} & {$[0.010]^{\star *}$} & {$[0.017]^{* *}$} & [0.022] & [0.032] & {$[0.010]^{\star *}$} & {$[0.010]^{* *}$} & {$[0.013]^{* *}$} & {$[0.010]^{* *}$} & {$[0.014]^{\star *}$} & {$[0.012]^{\star *}$} \\
\hline \multirow[t]{2}{*}{ Final_16_lg3 } & 0.011 & 0.017 & 0.043 & 0.02 & 0.006 & 0.013 & 0.008 & 0.019 & 0.01 & 0.021 & 0.007 \\
\hline & [0.009] & [0.010] & {$[0.017]^{\star}$} & [0.019] & [0.030] & [0.010] & [0.010] & {$[0.012]$} & [0.009] & {$[0.012]$} & [0.011] \\
\hline \multirow[t]{2}{*}{ Final_4 } & 0.019 & 0.019 & 0.037 & 0.026 & -0.009 & 0.02 & 0.016 & 0.013 & 0.021 & 0.029 & 0.017 \\
\hline & [0.014] & [0.015] & [0.024] & [0.026] & [0.038] & [0.015] & [0.016] & [0.016] & [0.015] & [0.022] & {$[0.017]$} \\
\hline \multirow[t]{2}{*}{ Final_4_Ig1 } & 0.058 & 0.057 & 0.143 & 0.079 & 0.056 & 0.071 & 0.047 & 0.087 & 0.049 & 0.049 & 0.074 \\
\hline & {$[0.012]^{\star *}$} & {$[0.015]^{* *}$} & {$[0.026]^{* *}$} & {$[0.030]^{\star *}$} & [0.049] & {$[0.014]^{* *}$} & {$[0.018]^{* *}$} & {$[0.014]^{* *}$} & {$[0.014]^{\star *}$} & {$[0.020]^{*}$} & {$[0.016]^{\star *}$} \\
\hline \multirow[t]{2}{*}{ Final_4_Ig2 } & 0.028 & 0.024 & 0.113 & 0.008 & 0.034 & 0.045 & 0.013 & 0.075 & 0.012 & 0.02 & 0.039 \\
\hline & {$[0.013]^{*}$} & [0.015] & {$[0.030]^{* *}$} & {$[0.026]$} & [0.034] & {$[0.017]^{\star *}$} & [0.016] & {$[0.016]^{\star *}$} & [0.013] & [0.020] & {$[0.016]^{*}$} \\
\hline \multirow[t]{2}{*}{ Final_4_Ig3 } & 0.008 & 0.015 & 0.035 & 0.012 & -0.007 & 0.019 & -0.004 & 0.026 & 0.003 & 0.025 & 0.005 \\
\hline & [0.016] & [0.019] & [0.026] & [0.029] & [0.047] & [0.016] & [0.021] & [0.020] & [0.016] & [0.026] & [0.017] \\
\hline \multirow[t]{2}{*}{ Champ } & 0.005 & -0.001 & 0.039 & 0.049 & -0.06 & 0.022 & -0.022 & -0.008 & 0.01 & 0.018 & -0.016 \\
\hline & [0.019] & [0.022] & [0.034] & [0.041] & {$[0.077]$} & [0.026] & [0.025] & [0.026] & [0.022] & [0.026] & {$[0.027]$} \\
\hline \multirow[t]{2}{*}{ Champ_lg1 } & 0.109 & 0.101 & 0.233 & 0.141 & 0.113 & 0.115 & 0.11 & 0.118 & 0.109 & 0.111 & 0.102 \\
\hline & {$[0.022]^{* *}$} & {$[0.023]^{* *}$} & {$[0.042]^{* *}$} & {$[0.045]^{* *}$} & {$[0.054]^{*}$} & {$[0.029]^{* *}$} & {$[0.032]^{* *}$} & {$[0.027]^{* *}$} & {$[0.023]^{* *}$} & {$[0.038]^{* *}$} & {$[0.023]^{* *}$} \\
\hline \multirow[t]{2}{*}{ Champ_lg2 } & 0.084 & 0.067 & 0.19 & 0.093 & 0.148 & 0.107 & 0.068 & 0.078 & 0.087 & 0.069 & 0.082 \\
\hline & {$[0.025]^{\star *}$} & {$[0.023]^{\star *}$} & {$[0.038]^{* *}$} & {$[0.038]^{*}$} & {$[0.077]$} & {$[0.029]^{\star *}$} & {$[0.030]^{*}$} & {$[0.026]^{\star *}$} & {$[0.028]^{\star *}$} & {$[0.030]^{*}$} & {$[0.032]^{* *}$} \\
\hline \multirow[t]{2}{*}{ Champ_lg3 } & 0.026 & 0.005 & 0.102 & 0.046 & 0.015 & 0.034 & 0.021 & 0.039 & 0.023 & 0.057 & 0.001 \\
\hline & {$[0.025]$} & [0.028] & {$[0.039]^{* *}$} & [0.041] & [0.051] & [0.031] & [0.028] & {$[0.022]$} & {$[0.028]$} & [0.029] & {$[0.030]$} \\
\hline
\end{tabular}


Table 2B. The Impact of Success in Men's Basketball and Football on SAT Score Sending

\begin{tabular}{|c|c|c|c|c|c|c|c|c|c|c|c|}
\hline \multicolumn{12}{|c|}{ Dependent Variable: Log Number of SAT Scores Sent by Subgroup } \\
\hline & Everyone & White & Black & Hispanic & Asian & Males & Females & Sports & No Sports & In-State & Out-of-State \\
\hline \multicolumn{12}{|l|}{ Football } \\
\hline \multirow[t]{2}{*}{ Top_20 } & 0.01 & 0.014 & -0.007 & 0.006 & -0.027 & 0.018 & 0.006 & 0.015 & 0.01 & 0.032 & 0.003 \\
\hline & [0.009] & [0.010] & [0.016] & [0.028] & {$[0.029]$} & {$[0.011]$} & [0.011] & [0.012] & {$[0.010]$} & {$[0.015]^{*}$} & [0.013] \\
\hline \multirow[t]{2}{*}{ Top_20_Ig1 } & 0.026 & 0.028 & 0.039 & 0.057 & 0.035 & 0.034 & 0.02 & 0.044 & 0.021 & 0.018 & 0.033 \\
\hline & {$[0.009]^{\star *}$} & {$[0.012]^{*}$} & {$[0.018]^{\star}$} & [0.029] & {$[0.030]$} & {$[0.011]^{\star *}$} & {$[0.011]$} & {$[0.013]^{* *}$} & {$[0.010]^{*}$} & {$[0.016]$} & {$[0.014]^{*}$} \\
\hline \multirow[t]{2}{*}{ Top_20_lg2 } & 0.022 & 0.021 & 0.001 & 0.049 & 0.041 & 0.03 & 0.016 & 0.034 & 0.019 & 0.021 & 0.027 \\
\hline & {$[0.008]^{\star *}$} & {$[0.010]^{*}$} & [0.016] & {$[0.023]^{\star}$} & {$[0.024]$} & {$[0.010]^{\star *}$} & [0.010] & {$[0.011]^{* *}$} & {$[0.009]^{*}$} & [0.011] & {$[0.011]^{*}$} \\
\hline \multirow[t]{2}{*}{ Top_10 } & 0.022 & 0.022 & 0.005 & 0.045 & 0.018 & 0.027 & 0.016 & 0.024 & 0.022 & 0.012 & 0.024 \\
\hline & {$[0.008]^{\star *}$} & {$[0.010]^{*}$} & [0.015] & {$[0.025]$} & {$[0.026]$} & {$[0.010]^{\star *}$} & {$[0.010]$} & {$[0.010]^{*}$} & {$[0.009]^{*}$} & [0.012] & {$[0.011]^{*}$} \\
\hline \multirow[t]{2}{*}{ Top_10_Ig1 } & 0.06 & 0.059 & 0.077 & 0.091 & 0.04 & 0.072 & 0.048 & 0.072 & 0.056 & 0.012 & 0.084 \\
\hline & {$[0.009]^{\star *}$} & {$[0.010]^{\star *}$} & {$[0.020]^{* *}$} & {$[0.022]^{* *}$} & {$[0.026]$} & {$[0.011]^{\star *}$} & {$[0.010]^{* *}$} & {$[0.011]^{* *}$} & {$[0.009]^{* *}$} & [0.015] & {$[0.011]^{\star *}$} \\
\hline \multirow[t]{2}{*}{ Top_10_Ig2 } & 0.027 & 0.027 & 0.042 & 0.036 & 0.01 & 0.035 & 0.018 & 0.021 & 0.029 & 0.013 & 0.037 \\
\hline & {$[0.008]^{\star *}$} & {$[0.010]^{\star *}$} & [0.021] & {$[0.017]^{\star}$} & {$[0.024]$} & {$[0.009]^{\star *}$} & [0.010] & {$[0.010]^{\star}$} & {$[0.009]^{\star *}$} & [0.014] & {$[0.010]^{\star *}$} \\
\hline \multirow[t]{2}{*}{ Champ } & 0.09 & 0.09 & 0.053 & 0.088 & -0.006 & 0.102 & 0.075 & 0.116 & 0.081 & 0.071 & 0.097 \\
\hline & {$[0.017]^{\star *}$} & {$[0.022]^{* *}$} & [0.035] & {$[0.036]^{*}$} & {$[0.086]$} & {$[0.023]^{* *}$} & {$[0.018]^{\star *}$} & {$[0.029]^{\star *}$} & {$[0.015]^{* *}$} & {$[0.026]^{* *}$} & {$[0.023]^{* *}$} \\
\hline \multirow[t]{2}{*}{ Champ_lg1 } & 0.118 & 0.114 & 0.192 & 0.19 & 0.05 & 0.137 & 0.101 & 0.165 & 0.102 & 0.064 & 0.163 \\
\hline & {$[0.016]^{* *}$} & {$[0.024]^{* *}$} & {$[0.040]^{\star *}$} & {$[0.041]^{\star *}$} & [0.084] & {$[0.023]^{* *}$} & {$[0.022]^{* *}$} & {$[0.025]^{\star *}$} & {$[0.016]^{* *}$} & {$[0.025]^{*}$} & {$[0.024]^{* *}$} \\
\hline \multirow[t]{2}{*}{ Champ_lg2 } & 0.017 & 0.001 & 0.083 & -0.034 & 0.057 & 0.047 & -0.011 & 0.015 & 0.019 & -0.011 & 0.04 \\
\hline & [0.022] & {$[0.026]$} & {$[0.047]$} & [0.040] & {$[0.097]$} & {$[0.026]$} & [0.032] & [0.033] & {$[0.021]$} & [0.035] & {$[0.022]$} \\
\hline School F.E.s & $x$ & $x$ & $x$ & $x$ & $x$ & $x$ & $x$ & $\mathrm{X}$ & $x$ & $x$ & $x$ \\
\hline Year F.E.s & $x$ & $x$ & $x$ & $x$ & $x$ & $x$ & $x$ & $x$ & $x$ & $x$ & $x$ \\
\hline School Trends & $x$ & $x$ & $x$ & $x$ & $x$ & $x$ & $x$ & $x$ & $x$ & $x$ & $x$ \\
\hline School Controls & $x$ & $x$ & $x$ & $x$ & $x$ & $x$ & $x$ & $x$ & $x$ & $x$ & $x$ \\
\hline $\mathbf{N}$ & $N=2431$ & $N=2427$ & $N=2429$ & $N=2426$ & $N=2411$ & $N=2430$ & $N=2429$ & $N=2428$ & $N=2431$ & $N=2419$ & 2430 \\
\hline R-squared & 0.997 & 0.995 & 0.994 & 0.993 & 0.981 & 0.996 & 0.997 & 0.994 & 0.997 & 0.995 & 0.996 \\
\hline
\end{tabular}

(linear trends), number of high school diplomas given out that year in the school's state, log average professor salary, log average real income in the school's state, and log tuition cost.

$*$ significant at $5 \%, * *$ significant at $1 \%$ 
Table 3. The Impact of Success in Women's

Basketball on SAT Score Sending

\begin{tabular}{lcc}
\hline \hline & Log(\# SATs) & Log(\# Female SATs) \\
\cline { 2 - 3 } Basketball & & \\
Final_4 & 0.004 & -0.002 \\
& {$[0.016]$} & {$[0.020]$} \\
Final_4_Ig1 & -0.004 & -0.007 \\
& {$[0.017]$} & {$[0.018]$} \\
Final_4_Ig2 & 0.002 & 0 \\
& {$[0.016]$} & {$[0.018]$} \\
Final_4_Ig3 & 0.003 & -0.004 \\
& {$[0.017]$} & {$[0.019]$} \\
Champ & -0.023 & -0.027 \\
& {$[0.018]$} & {$[0.026]$} \\
Champ_Ig1 & 0.007 & 0.007 \\
& {$[0.024]$} & {$[0.030]$} \\
Champ_Ig2 & -0.012 & -0.001 \\
& {$[0.025]$} & {$[0.034]$} \\
Champ_Ig3 & -0.013 & -0.003 \\
& {$[0.022]$} & {$[0.028]$} \\
Controls \& F.E.s & $\mathrm{X}$ & $\mathrm{X}$ \\
Observations & $\mathrm{N}=2431$ & $\mathrm{~N}=2430$ \\
R-squared & 0.997 & 0.997 \\
\hline Not & &
\end{tabular}

Notes: Robust standard errors are presented in brackets. Control

variables that are included are school and year fixed effects, school*year

(linear trends), number of high school diplomas given out that year in the school's state, log average professor salary, log average real income in the school's state, and log tuition cost.

$*$ significant at $5 \%, * *$ significant at $1 \%$ 
Table 4. The Impact of Close Victories

\begin{tabular}{|c|c|c|}
\hline & \multicolumn{2}{|c|}{ Dep Var: Log(Apps Everyone) } \\
\hline & Margin $<=2$ & Margin $<=1$ \\
\hline Won & $\begin{array}{l}0.022 \\
(.014)\end{array}$ & $\begin{array}{l}0.027 \\
(.019)\end{array}$ \\
\hline Won_lg1 & $\begin{array}{c}0.045 \\
(.014)^{* * *}\end{array}$ & $\begin{array}{c}0.054 \\
(.016)^{* * *}\end{array}$ \\
\hline Won_lg2 & $\begin{array}{c}0.038 \\
(.014)^{* \star *}\end{array}$ & $\begin{array}{c}0.046 \\
(.020)^{* *}\end{array}$ \\
\hline Won_lg3 & $\begin{array}{l}-0.004 \\
-0.014\end{array}$ & $\begin{array}{c}0 \\
-0.019\end{array}$ \\
\hline Lost & $\begin{array}{c}0.013 \\
-0.013\end{array}$ & $\begin{array}{c}0.027 \\
-0.015\end{array}$ \\
\hline Lost_Ig1 & $\begin{array}{c}0.023 \\
(.012)^{* *}\end{array}$ & $\begin{array}{c}0.039 \\
(.015)^{* * *}\end{array}$ \\
\hline Lost_lg2 & $\begin{array}{l}0.017 \\
(.014)\end{array}$ & $\begin{array}{l}0.021 \\
(.020)\end{array}$ \\
\hline Lost_Ig3 & $\begin{array}{l}0.011 \\
(.013)\end{array}$ & $\begin{array}{c}0 \\
(.019)\end{array}$ \\
\hline $\begin{array}{l}\text { School F.E. } \\
\text { School Trends }\end{array}$ & $\begin{array}{l}x \\
X\end{array}$ & $\begin{array}{l}x \\
x\end{array}$ \\
\hline Other Controls & $\mathrm{x}$ & $\mathrm{x}$ \\
\hline Observations & 2431 & 2431 \\
\hline R-Squared & 0.997 & 0.997 \\
\hline
\end{tabular}

Notes: Robust standard errors are presented in brackets. Control variables that are included are school and year fixed effects, school*year (linear trends), number of high school diplomas given out that year in the school's state, log average professor salary, log average real income in the school's state, and log tuition cost. Any team that won by the indicated margin during any game in the NCAA Tournament was coded as a team that "won" while the opposing team was coded as a team that "lost".

$*$ significant at $5 \%, * *$ significant at $1 \%$ 